Research Paper

\title{
DAXX/ATRX and MEN1 genes are strong prognostic markers in pancreatic neuroendocrine tumors
}

\author{
Joo Kyung Park ${ }^{1, *}$, Woo Hyun Paik ${ }^{2, *}$, Kyoungbun Lee ${ }^{3, *}$, Ji Kon Ryu², Sang Hyub \\ Lee $^{2}$ and Yong-Tae Kim ${ }^{2}$ \\ ${ }^{1}$ Division of Gastroenterology, Department of Medicine, Samsung Medical Center, Sungkyunkwan University School of \\ Medicine, Seoul, Korea \\ ${ }^{2}$ Department of Internal Medicine and Liver Research Institutute, Seoul National University Hospital, Seoul National University \\ College of Medicine, Seoul, Korea \\ ${ }^{3}$ Department of Pathology, Seoul National University Hospital, Seoul National University College of Medicine, Seoul, Korea \\ *These authors contributed equally to this work
}

Correspondence to: Ji Kon Ryu, email: jkryu@snu.ac.kr

Keywords: DAXX/ATRX, MEN, neuroendocrine tumor

Received: April 30, $2016 \quad$ Accepted: May 01, $2017 \quad$ Published: May 18, 2017

Copyright: Park et al. This is an open-access article distributed under the terms of the Creative Commons Attribution License 3.0 (CC BY 3.0), which permits unrestricted use, distribution, and reproduction in any medium, provided the original author and source are credited.

\section{ABSTRACT}

Background: PanNETs shows heterogeneous biological behaviors. The aim was to investigate prognostic markers based on most frequently mutated genes in PanNETs. Results: There was a total of 76 patients (M: 39, F: 37) with pathologically proven PanNETs. ATRX/DAXX and MEN1 protein expression was detected in $16(21 \%)$ and $31(41 \%)$ patients, respectively. The mean OS of the total study patients was 16 years, and DFS was 17 years among the 68 patients with curative resections. PanNETs presented with distant metastasis or loss of ATRX/DAXX protein expression was the independent prognostic factors associated with poor OS. In curative resected PanNETs, there was no significant difference in the mean DFS according to ATRX/DAXX or MEN1 protein. However, there was statistically significant difference in survival after the recurrence according to the expression of ATRX/DAXX protein; Y/N: 10 vs. 15 years, $p<0.001$. In metastatic PanNETs, we could find out OS was significantly longer in negative protein expression of ATRX/DAXX and MEN1 groups; 7 vs. 1 years, $p<0.001$, 6 vs. 2 years, $p=0.02$, respectively.

Materials and Methods: The histologically proven PanNETs were enrolled and the clinicopathologic and genetic alterations were evaluated.

Conclusions: Protein expression of MEN1 and DAXX/ATRX can be prognostic markers for PanNETs. Further investigation in genetic alterations of PanNETs may give us insights understanding the behavior of PanNETs.

\section{INTRODUCTION}

Pancreatic neuroendocrine tumors (PanNETs) are rare neoplasms which have an incidence of approximately one per 100,000 individuals per year and represent 3\% of all pancreatic tumors $[1,2]$. PanNET is an important form of pancreatic neoplasia and the 10-year survival rate is $40 \%$ [3, 4]. Several studies have documented a trend towards the increasing incidence and prevalence of PanNETs [5]. Although usually indolent, the biological behavior of PanNET ranges varies from benign to malignant ones, and some PanNETs may also show very aggressive behavior with rapid progression and poor prognosis [6-11].Predictors of prognosis include nonfunctioning tumor, tumor size, the presence and the site of metastases, the degree of tumor differentiation, Ki-67 and spontaneous tumor growth rapidity [12-16]. However, the prognostic factors of PanNET are still debatable because of their rarity and heterogeneity of biologic and clinical features. 
Recently, Jiao et al. and Marinoni et al. both conducted the large-scale mutational analysis with the help of high throughput techniques in patients with PanNETs so far. First of all, Jiao et al. reported that the gene mutations in MEN1 and DAXX (death-domain-associated protein)/ ATRX $(\alpha$ thalassemia/mental retardation syndrome $\mathrm{X}$-linked) genes emerged as the most frequent molecular events and associated with better prognosis [17]. On the other hands, Marinoni et al. reported that the loss of DAXX and ATRX are related with chromosome instability and poor survival of patients with PanNETs which seemed to contradictory to the results of Jiao et al. study $[17,18]$. The aims of this study were to identify the genetic alterations which enable us to predict the prognosis and further more survival of the patients with PanNETs.

\section{RESULTS}

\section{Characteristics of the study patients}

The baseline characteristics were described in Table 1. The total of 76 patients with pathologically proven PanNETs was enrolled in tertiary, teaching hospital. There were 39 males (51\%) and the median age of study patients was 54 years old (range 21 to 76 years). There were 71 patients $(93 \%)$ who underwent operation including palliative surgery and 68 patients $(96 \%)$ had curative resections; 51 patients in stage IA,B, 16 in IIA,B and 1 patient who had resection for pancreas mass and single solitary metastasis resection from the liver. Among the resected PanNETs, there were 4 functioning tumors; 2 insulinomas, 1 gastrinoma, and 1 somatostatinoma. The median size of tumor was $23 \mathrm{~mm}$ ranged from 3 to 200 $\mathrm{mm}$ and the followings is the location of PanNETs; head \& uncinated: 40 , body \& tail: 34 and multifocal: 2 . In addition, there were $9(12 \%)$ patients who were presented with metastatic PanNETs; AJCC stage IA, IB: 51, IIA, IIB: 16, III:0, IV 9 patients. Among the 68 resected PanNETs, 7 $(10 \%)$ patients had recurrences after the curative resection.

\section{Pathologic characteristics}

All study patients were pathologically proven as PanNETs and the grading system from 2010 WHO classification of neuroendocrine tumors was used for the study patients; G1: 53 (70\%), G2: 20 (26\%) and G3: 3 (4\%). IHC staining results with ATRX/DAXX and MEN1 are shown in Figure 1 and Table 1. In Figure 1, panel A-C showed the positive IHC staining result of DAXX/ ATRX and MEN1 which indicated positive expression for DAXX/ATRX and MEN1 proteins. Panel D-I showed negative staining results due to the loss of ATRX/DAXX and MEN1 protein expression. Among the study patients, positive expression for ATRX/DAXX and MEN1 protein were detected in $16(21 \%)$ and $31(41 \%)$ patients, respectively. There were $41(54 \%)$ patients who had both negative expressions for ATRX/DAXX and MEN1 proteins.

\section{Overall survival and disease-free survival of the study patients}

As we mentioned above, there was a total of 76 study patients and 68 patients who underwent curative resection among them. The mean overall survival (OS) was 15.5 years (95\% CI 13.8-17.1 years) and 16 out of 76 study patients (21\%) died during the follow-up (Figure 2A). In addition, DFS was 16.5 years (ranged from 14.9 to 18.1 years) among the 68 patients with the curative resections (Figure 2B).

\section{Prognostic factors affecting OS of the study patients}

The following clinical and histological parameters associated with OS were analyzed: age, staging at the time of diagnosis, lymph node status, curative intent surgery, WHO grade and protein expression status of ATRX/DAXX and MEN1. Among them, distant metastasis (mean OS 3.0 years vs. 16.9 years, $p<0.001$ ), lymph node positive (mean OS 8.8 years vs. 16.0 years $p=0.025$ ), curative intent surgery (mean OS 16.7 years vs. 2.9 years, $p<$ 0.001 ), WHO grade (mean OS G1 16.4 years vs. G2 15.4 years vs. G3 0.6 years, $p<0.001$ ), and negative expression for ATRX/DAXX protein (mean OS 15.3 years vs. 10.8 years, $p<0.001$ ) were significant prognostic factors associated with OS in univariate analysis (Figure 3A-3E). On the other hands, MEN1 protein expression status did not have statistically significant difference in OS (mean OS 16.4 years vs. 14.0 years, $p=0.08$ ). In multivariate analysis, patients presented with positive expression of ATRX/DAXX protein (HR 3.809, 95\% CI 1.064-13.630, $p=0.04)$ was the only independent prognostic factors associated with poor OS (Table 2).

\section{Subgroup analysis in curatively resected PanNETs vs. metastatic PanNETs}

There was no significant difference in the mean disease-free survival according to ATRX/DAXX (Y/N: 17.1 years vs. 15.4 years, $p=0.77$ ) or MEN1 protein expression status $(\mathrm{Y} / \mathrm{N}: 16.5$ years vs. 16.0 years, $p=0.47$ ) in curatively resected PanNETs (Figure 4A). However, among the patients with curatively resected PanNETs, both negative protein expression tumors seemed to have longer DFS which was opposite to the result that negative ATRX/DAXX protein expression was the independent prognostic factor for longer OS in the study patients. Therefore, we also evaluated unique parameter such as survival after the recurrence since PanNETs have significantly longer survival compared to PDACs. There was clearly statistically significant difference in 
Table 1: Clinicopathologic characteristics

\begin{tabular}{|c|c|}
\hline Terms & $n=76$ \\
\hline Age (median, range, yrs) & $54(21-76)$ \\
\hline $\operatorname{Sex}(M: F)$ & 39: 37 \\
\hline Follow-up (median, range, yrs) & $5.9(1-18.8)$ \\
\hline Operation (\%) & $71(93 \%)$ \\
\hline Curative resection & 68 \\
\hline Palliative operation & 3 \\
\hline Functioning tumors $(\%)$ & $4(5 \%)$ \\
\hline Size of tumors (median, range, $\mathrm{mm}$ ) & $23(3-200)$ \\
\hline \multicolumn{2}{|l|}{ Location } \\
\hline Head, uncinate process & $40(53 \%)$ \\
\hline Body, tail & $34(45 \%)$ \\
\hline Multifocal & $2(3 \%)$ \\
\hline \multicolumn{2}{|l|}{ AJCC Stage } \\
\hline IA, IB & $51(67 \%)$ \\
\hline IIA, IIB & $16(21 \%)$ \\
\hline III & 0 \\
\hline IV & $9(12 \%)$ \\
\hline Recurrence after curative resection & $7(10 \%)$ \\
\hline $\begin{array}{c}\text { Grade } \\
\text { G1 } \\
\text { G2 } \\
\text { G3 } \\
\end{array}$ & $\begin{array}{c}53(70 \%) \\
20(26 \%) \\
3(4 \%)\end{array}$ \\
\hline ATRX protein expression $(-)$ & $55(72 \%)$ \\
\hline DAXX protein expression (-) & $54(71 \%)$ \\
\hline MEN1 protein expression (-) & $45(59 \%)$ \\
\hline
\end{tabular}

survival after the recurrence according to ATRX/DAXX protein expression status; $\mathrm{Y} / \mathrm{N}$ : 9.7 years vs. 15.3 years, $p<0.001$ in Figure 4B. On the other hand, MEN1 protein expression status did not make significant difference in survival after the recurrence; Y/N: 12.4 years vs. 16.4 years, $p=0.08$. However, there was a still tendency to have longer survival after the recurrence in patients with negative MEN1 protein expression.

In metastatic PanNETs, we could find out OS was significantly longer in negative ATRX/DAXX and MEN1 protein groups; Figure 5A: 6.5 years vs. 1.1 years, $p<0.001$, Figure 5B: 6.2 years vs. 1.5 years, $p=0.03$, respectively.

\section{DISCUSSION}

Hallmarks of PanNETs are having heterogeneous and wide spectrum of clinical paths, however, there is absence of strong prognostic markers for recurrences [19]. The investigation and managements needs to be individualized for each patient and therefore, finding of surrogate markers to predict its prognosis can be very important [20]. The most frequently mutated genes have been reported with the help of high throughput techniques and they are the followings; MEN1 and DAXX/ATRX genes. Somatic mutations of MEN1 and DAXX/ATRX genes were inactivating mutations [17, 21-24]. DAXX/ 
ATRX genes specify proteins implicated in chromatin remodeling. MEN1 gene encodes menin, a histone methyltransferase complex and acts as a tumor suppressor. DAXX/ATRX genes, either of the two subunits consists of a transcription/chromatin remodeling complex [17, 21-24]. To explore and investigate the prognostic markers of PanNETs, we have investigated 76 patients with pathologically proven PanNETs based on genetic alterations and had relatively thorough and longer followup data compared to the previous studies $[17,18]$. ATRX/ DAXX (either one of the genes since they are mutually exclusive) and MEN1 protein expression were detected in $16(21 \%)$ and $31(41 \%)$ patients, respectively. Jio et al. have reported that mutation with ATRX/DAXX or ATRX/DAXX and MEN1 have significantly longer OS in metastatic PanNETs [17]. Marinoni et al. also collected 149 primary PanNETs from the tumor registry and studied the correlation of loss of DAXX or ATRX expression using IHC staining [18]. The loss of DAXX or ATRX correlated with tumor stage and metastasis, reduced time of relapsefree survival and decreased time of tumor-associated survival [18]. Those two studies have been the relatively large-scale ones compared to previous studies so far and unfortunately, they have suggested different prognostic outcomes according to the ATRX/DAXX mutational status $[17,18]$. When we took down the data closely, Jio et al. evaluated OS among the 27 metastatic PanNETs and Marinoni et al. used two different data sets which had 142 and 101 PanNETs including metastatic patients. However, those two sets of data of Marinoni et al. couldn't get the complete survival data; 57/142 (67\%) and 37/101 (37\%) and metastatic data as well; 104/142 (73\%) and 17/101 (17\%). In addition, since Marinoni et al. study patients were registered from the cancer registries in two different institutions and their follow-ups took place in local general practitioners, and clinical data regarding survival, TNM stage and clinical courses such as recurrence data were not all completely acquired in large number of study patients. Therefore, the total analyzed data became very small number of patients and the important clinical data was incomplete. Unlikely to those previous studies, we have completed all the data set with long-term follow-up and subgroup analyses were done in metastatic and curatively resected PanNETs. First of all, PanNETs presented with distant metastasis (HR 10.124, 95\% CI 2.727-37.584, $p=0.001)$ and positive ATRX/DAXX protein expression (HR 4.465, 95\% CI 1.382-14.428, $p=0.01$ ) were the independent prognostic factors associated with poor OS from multivariate analysis in total study patients. Among the 68 patients with curatively resected PanNETs, ATRX/DAXX or MEN1 protein expression positive tumors seemed to have longer DFS similar to Marinoni study, but it was not statistically significant. Moreover, PanNETs usually have longer survival and heterogeneous clinical courses compared to PDACs (pancreatic ductal adenocarcinomas), we have analyzed unique clinical
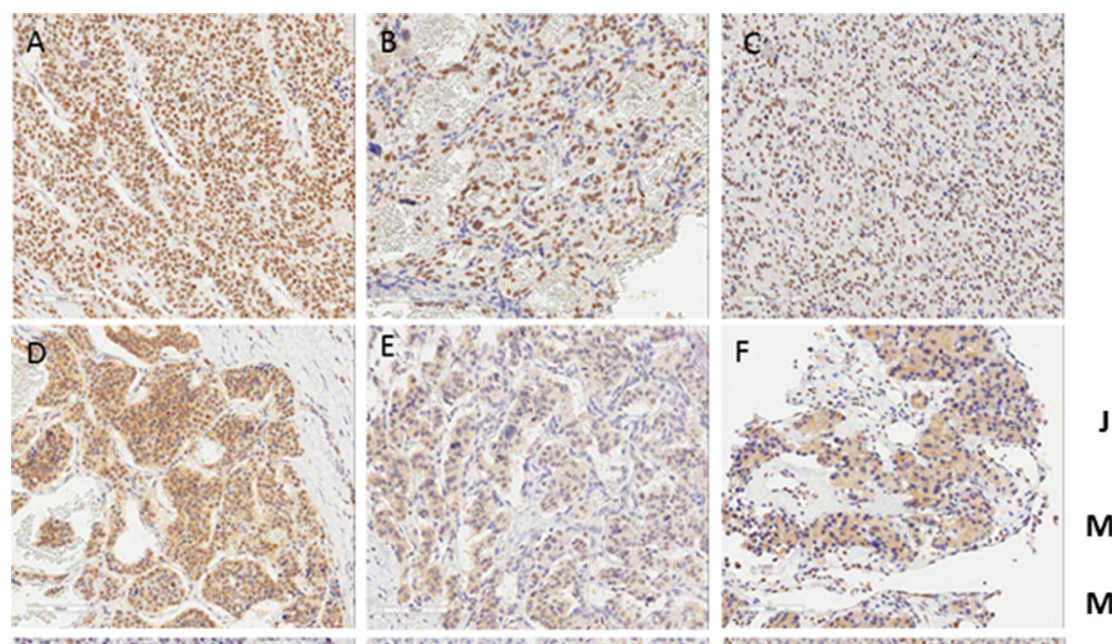

J $\quad$ ATRX/DAXX (-) ATRX/DAXX (+)

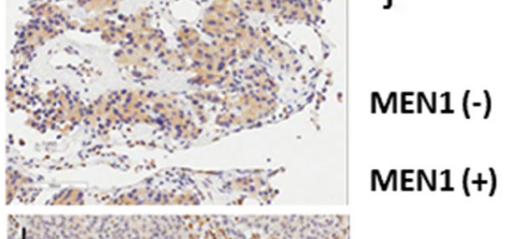

41

4
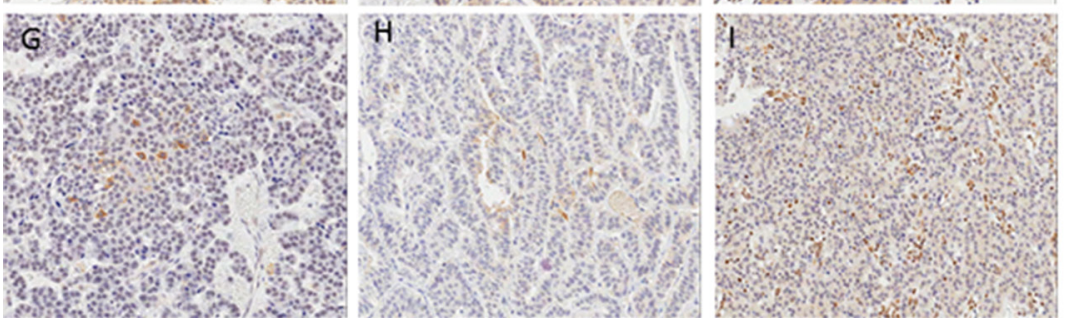

19

12

Figure 1: Immunohistochemical staining of MEN1 (A)(D)(G), ATRX (B)(E)(H), and DAXX (C)(F)(I). (A-C) Positive nuclear staining of MEN1, ATRX, and DAXX (D-F) Positive cytoplasmic staining of MEN1, ATRX, and DAXX (G-I) Negative staining of MEN1, ATRX, and DAXX (all pictures x200) (J) Expression status of MEN1 and ATRX/DAXX according to the immunohistochemical staining. 
variable associated with genetic alterations such as survival after the metastasis in curative resected PanNETs. There was statistically significant difference in survival after the recurrence according to ATRX/DAXX protein expression status in curatively resected PanNETs. PanNETs with negative ATRX/DAXX protein expression had significantly longer survival after the recurrences; 15.3 vs. 9.7 years, $p<0.001$. Also, OS of metastatic PanNETs was significantly longer in negative ATRX/ DAXX and MEN1 protein expression group; 6.5 vs. 1.1 years, $p<0.001,6.2$ vs. 1.5 years, $p=0.03$, respectively. Interestingly, metastatic PanNETs and recurred PanNETs after the curative resections have significant different survival according to the mutational status of ATRX/ DAXX or MEN1 genes and these result coincided with Jiao et al. study. However, we have not done functional studies regarding MEN1 and DAXX/ATRX. It might be also possible that ATRX/DAXX mutually exclusive genes and MEN1 gene mutations would cause silencing the protein expression, and they have been reported to affect the prognosis of PanNETs. The possible mechanisms of MEN1 and DAXX/ATRX in pathogenesis or progression have been reported as follows. The protein product of MEN1, menin, is an substantial component of the

A

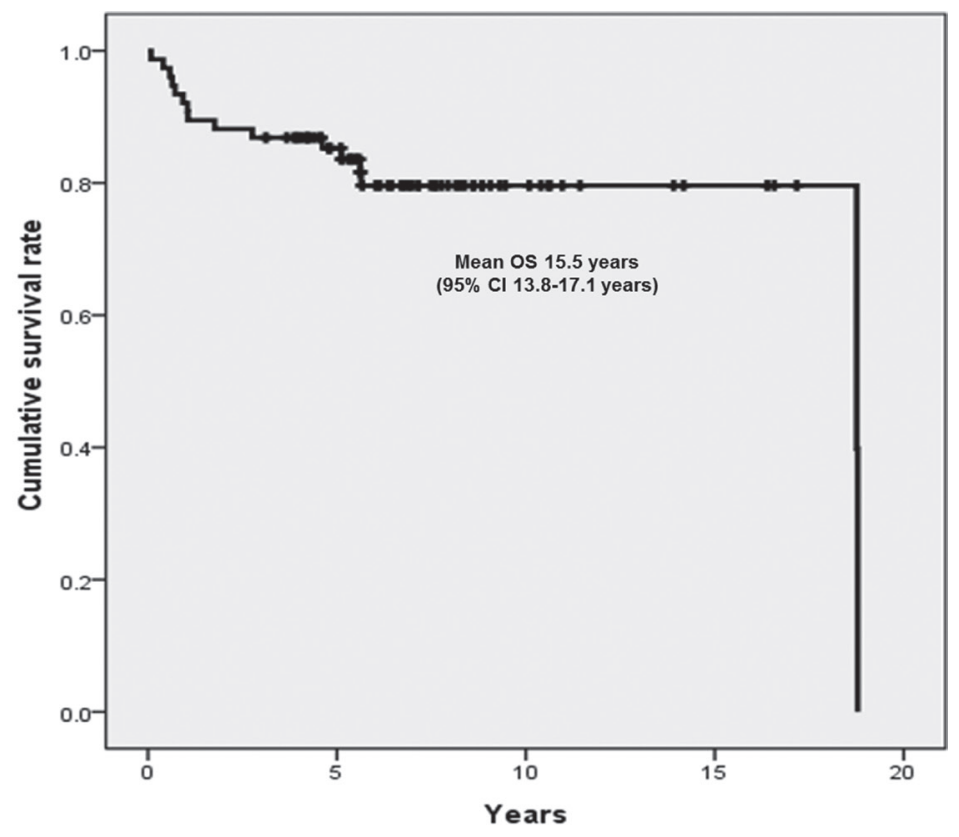

B

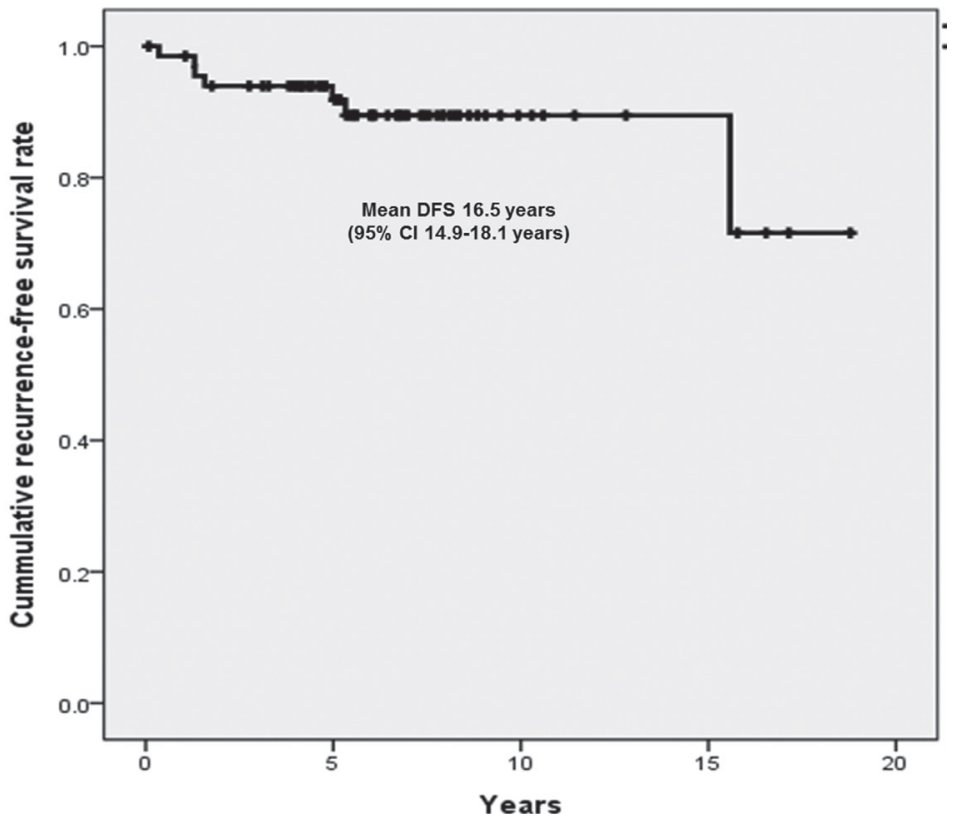

Figure 2: Kaplan-Meier curve of overall survival and DFS of the study patients. (A) OS of the total of 76 study patients (B) DFS of the patients who underwent curative resection. 
A

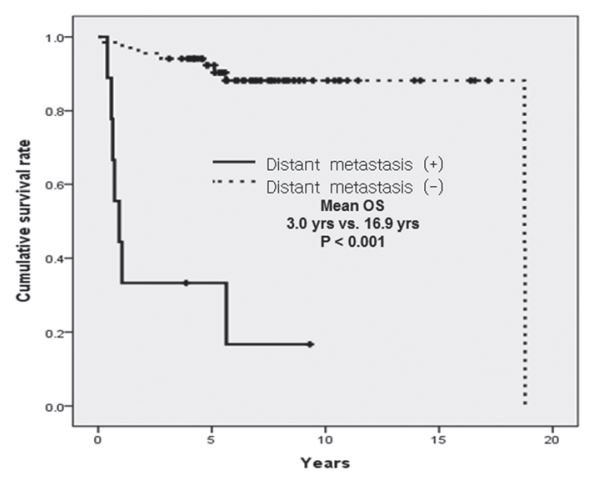

\begin{tabular}{|l|c|c|c|c|c|}
\hline Patients at risk (years) & 1 & 2 & 3 & 4 & 5 \\
\hline Distant metastasis $(+)(n=9)$ & 4 & 3 & 3 & 2 & 2 \\
\hline Distant metastasis $(-)(n=67)$ & 66 & 64 & 63 & 60 & 50 \\
\hline
\end{tabular}

\section{C}

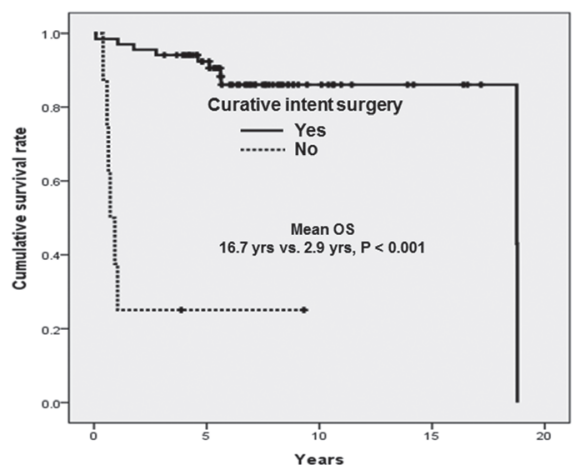

\begin{tabular}{|l|c|c|c|c|c|}
\hline Patients at risk (years) & 1 & 2 & 3 & 4 & 5 \\
\hline Curative intent surgery Y $(n=68)$ & 67 & 65 & 64 & 61 & 51 \\
\hline Curative intent surgery N (n=8) & 3 & 2 & 2 & 1 & 1 \\
\hline
\end{tabular}

E

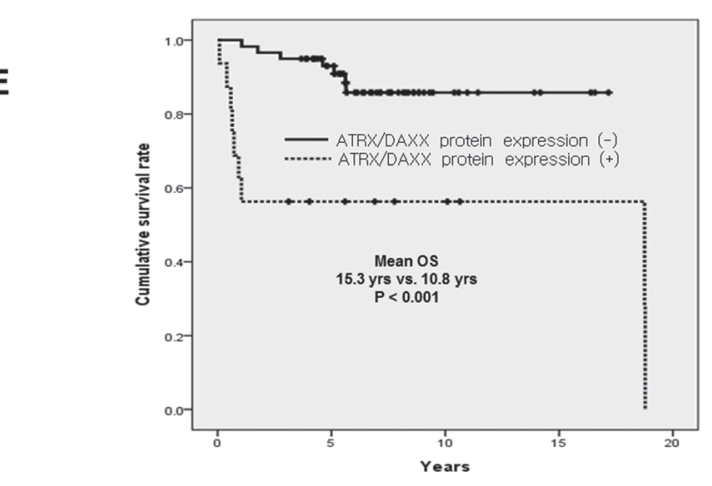

B

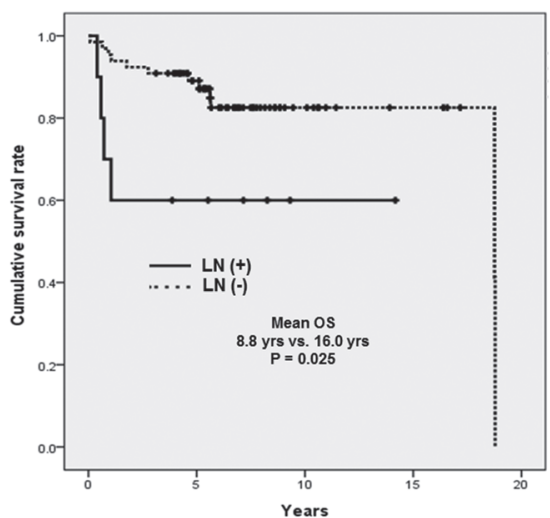

\begin{tabular}{|l|c|c|c|c|c|}
\hline Patients at risk (years) & 1 & 2 & 3 & 4 & 5 \\
\hline LN (+) (n=10) & 7 & 6 & 6 & 5 & 5 \\
\hline LN (-) (n= 66) & 63 & 61 & 60 & 57 & 47 \\
\hline
\end{tabular}

D

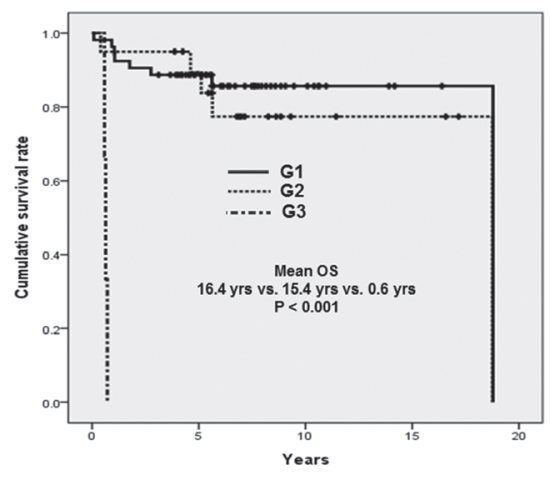

\begin{tabular}{|l|c|c|c|c|c|}
\hline Patients at risk (years) & 1 & 2 & 3 & 4 & 5 \\
\hline $\mathbf{G 1}(\mathbf{n}=53)$ & 51 & 48 & 47 & 44 & 36 \\
\hline G2 $(\mathbf{n = 2 0})$ & 19 & 19 & 19 & 18 & 16 \\
\hline G3 $(\mathbf{n}=3)$ & 0 & 0 & 0 & 0 & 0 \\
\hline
\end{tabular}

\begin{tabular}{|l|c|c|c|c|c|}
\hline Patients at risk (years) & 1 & 2 & 3 & 4 & 5 \\
\hline ATRX/DAXX protein expression $(-)(n=60)$ & 60 & 58 & 57 & 54 & 45 \\
\hline ATRX/DAXX protein expression $(+)(n=16)$ & 10 & 9 & 9 & 8 & 7 \\
\hline
\end{tabular}

Figure 3: Univariate analyses of OS according to the clinicopathologic factors. (A) No distant metastasis vs. metastatic PanNETs at the time of diagnosis (mean OS 3.0 yrs vs. $16.9 \mathrm{yrs}, p<0.001$ ) (B) Lymph node positive vs. negative at the time of diagnosis (mean OS 8.8 yrs vs. 16.0 yrs, $p=0.025$ ) (C) Whether curative intent surgery was done or not (mean OS 16.7 yrs vs. 2.9 yrs, $p<0.001)$ (D) WHO grade (mean OS G1 16.4 yrs vs. G2 15.4 yrs vs. G3 0.6 yrs, $p<0.001$ ) and (E) Negative for ATRX/DAXX protein expression (N/Y: mean OS 15.3 yrs vs. 10.8 yrs, $p<0.001$ ) were statistically significant factors associated with OS among the study patients. 
Table 2: Multivariate analysis of prognostic factors affecting overall survival

\begin{tabular}{l|c|c|}
\hline Variable & HR (95\% CI) & P value \\
\hline Lymph node positive & $0.482(0.085-2.722)$ & 0.409 \\
\hline Curative intent surgery & $0.412(0.026-6.605)$ & 0.531 \\
\hline Distant metastasis & $7.702(0.828-71.638)$ & 0.073 \\
\hline WHO grade & $1.611(0.676-3.840)$ & 0.282 \\
\hline ATRX/DAXX protein expression positive & $3.809(1.064-13.630)$ & 0.040 \\
\hline
\end{tabular}

A
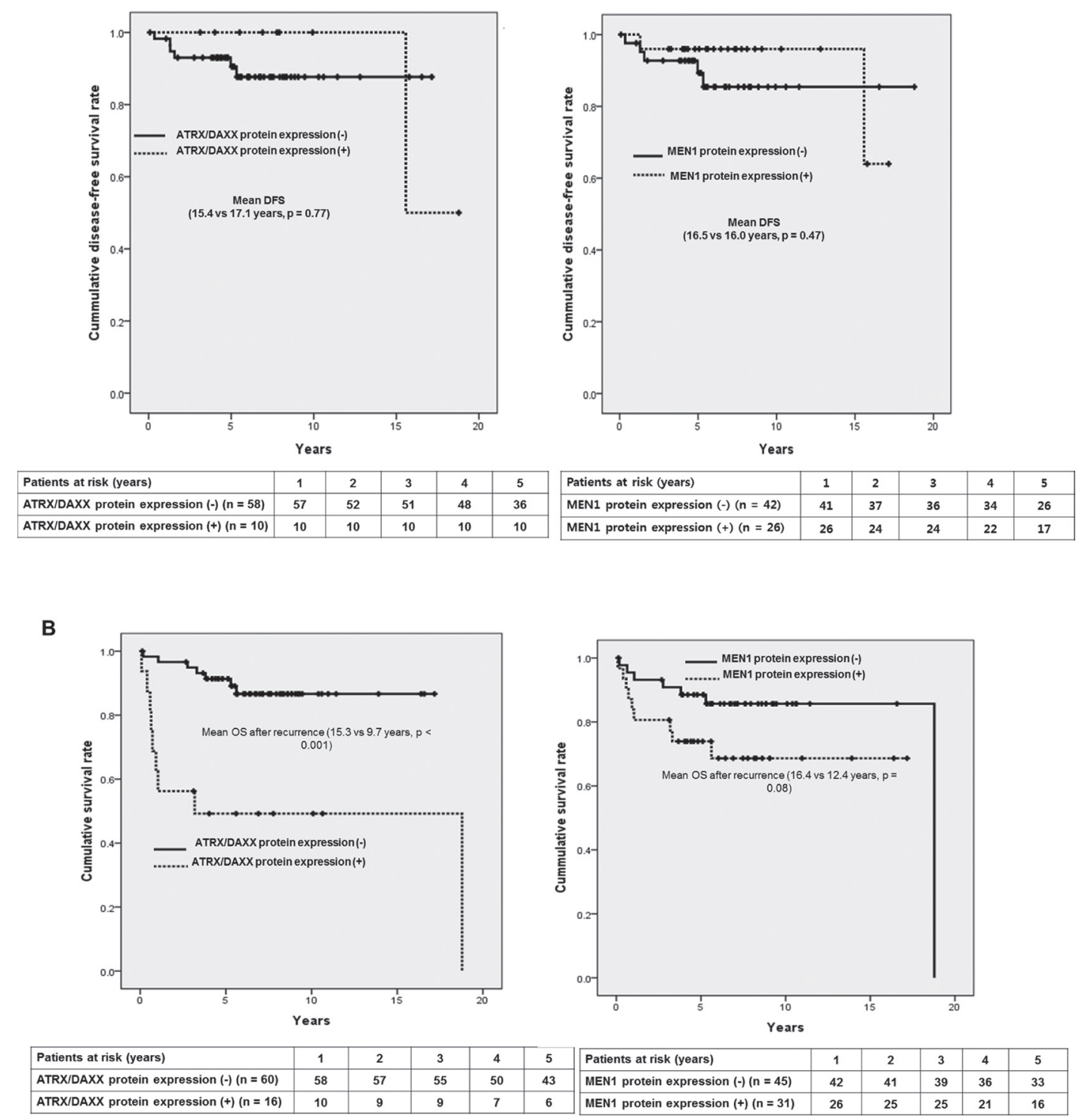

Figure 4: Prognostic factors affecting survival in patients with curatively resected PanNETs. (A) Kaplan-Meier curves of DFS for ATRX/DAXX protein expression (N/Y: $15.4 \mathrm{yrs}$ vs. $17.1 \mathrm{yrs}, p=0.77)$ and MEN1 protein expression (N/Y: $16.0 \mathrm{yrs}$ vs. $16.4 \mathrm{yrs}$, $p=0.47$ ) (B) Kaplan-Meier curves of OS after the recurrence for ATRX/DAXX protein expression (N/Y: $15.3 \mathrm{yrs}$ vs. $9.7 \mathrm{yrs}, p<0.001)$ and MEN1 protein expression (N/Y: 16.4 yrs vs. $12.4 \mathrm{yrs}, p=0.08)$. 
MLL/SET1-like histone methyltransferase complex and regulates chromatin remodeling, functioning as activator or suppressor of gene transcription according to the cell type [25]. For example, menin acts as a tumor activator in promoting MLL-dependent leukemias, but acts as a tumor suppressor in neuroendocrine tumors [25]. As we have showed in Figure 4A, patients with positive for MEN1 protein expression had significantly longer DFS compared to negative for MEN1 protein expression group. DAXX mutation decreases p53 levels, diminishing the check point for cellular/DNA damages [25]. In addition, changes in the nucleotide sequence often resulted in nonsense mutations that are generally relevant to tumor suppressor genes [25]. Furthermore, Heaphy et al. reported a perfect correlation between the loss of ATRX or DAXX function and the presence of a telomerase-independent telomere maintenance mechanism known as alternative lengthening of telomeres (ALT) [26]. The association of ATRX and DAXX inactivation with the ALT phenotype might explain previous observations in other tumor types that connected the ALT phenotype with improved prognosis [27, 28]. Thompson et al. also reported that the resulting ALT phenotype is the basis for the good prognosis; probably by preventing the initiation of widespread chromosomal

A

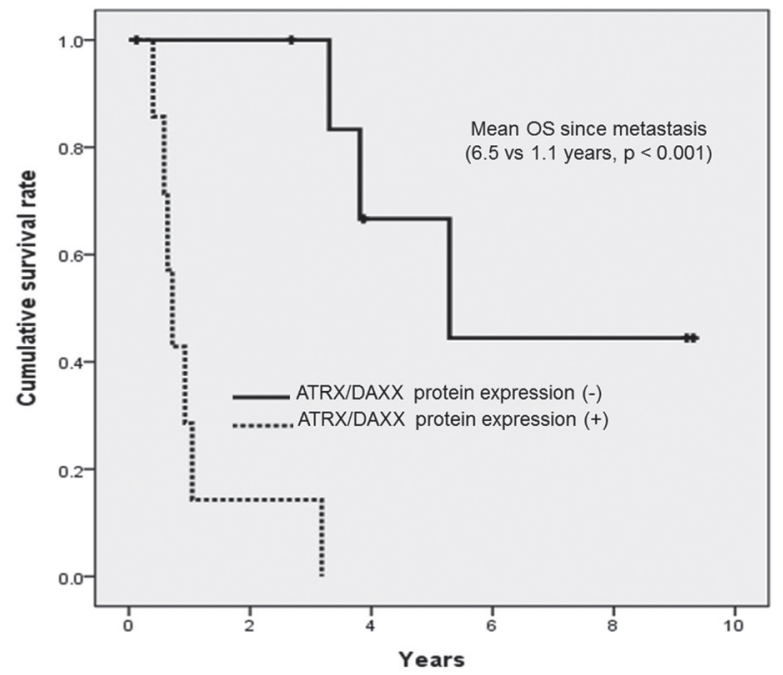

\begin{tabular}{|l|l|l|l|l|l|}
\hline Patients at risk (years) & $\mathbf{1}$ & $\mathbf{2}$ & $\mathbf{3}$ & $\mathbf{4}$ & $\mathbf{5}$ \\
\hline ATRX/DAXX protein expression $(-)(\mathrm{n}=\mathbf{8})$ & $\mathbf{5}$ & $\mathbf{5}$ & $\mathbf{5}$ & $\mathbf{3}$ & 3 \\
\hline ATRX/DAXX protein expression $(+)(\mathrm{n}=\mathbf{7})$ & 2 & 1 & $\mathbf{1}$ & 0 & 0 \\
\hline
\end{tabular}

B

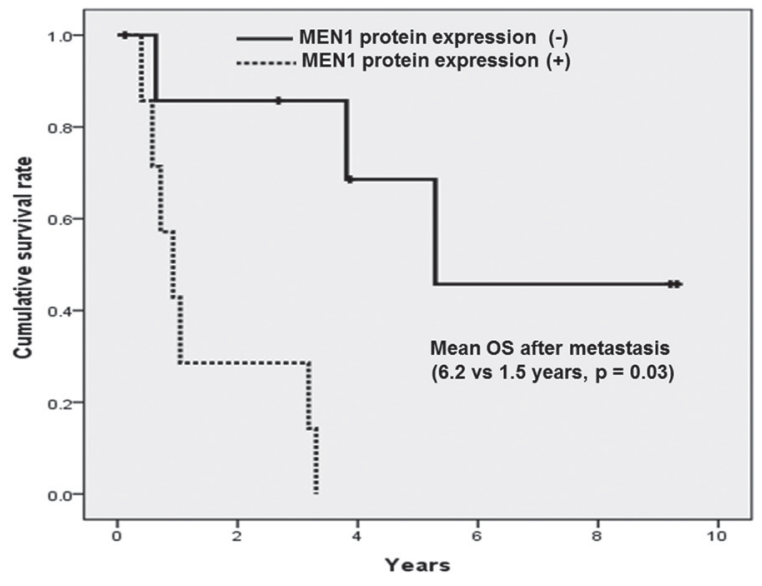

\begin{tabular}{|l|l|l|l|l|l|}
\hline Patients at risk (years) & 1 & 2 & 3 & 4 & 5 \\
\hline MEN1 protein expression $(-)(n=8)$ & 6 & 6 & 5 & 3 & 3 \\
\hline MEN1 protein expression $(+)(n=7)$ & 3 & 2 & 2 & 0 & 0 \\
\hline
\end{tabular}

Figure 5: Prognostic factors affecting survival in patients with metastatic PanNETs. (A) Kaplan-Meier curves of OS according to the protein expression of ATRX/DAXX (N/Y: 6.5 yrs vs. 1.1 years, $p<0.001)$ (B) Kaplan-Meier curves of OS according to the protein expression of MEN1 (N/Y: 6.2 yrs vs. $1.5 \mathrm{yrs}, p=0.03)$. 
instability [29]. Jiao et al. reported that PanNETs patients with altered ATRX or DAXX genes showed better prognosis than those with wild-type tumors [17]. In Figure 3E, we have also showed that the patients without expression of ATRX/DAXX protein (presumably altered ATRX or DAXX genes) had significantly longer OS compared to positive for ATRX/DAXX protein group.

Understanding of the molecular mechanisms leading to the development of PanNETs can be invaluable for a more personalized treatment approach. Here, we have studied whole sets of PanNETs with different clinical presentations; curatively resected, metastatic and recurrences after the curative resections. ATRX or DAXX loss was proved to be an independent predictor for OS of PanNETs in a multivariate Cox regression analysis including well-established risk factors; tumor stage and tumor grade. Further investigation in genetic alterations of PanNETs may not only give us insights to discover strong prognostic markers for survival but also to predict the behavior of PanNETs.

\section{MATERIALS AND METHODS}

\section{Study patients}

The total of 177 patients who had pathologically proven PanNETs between January 1990 and March 2012 at Seoul National University Hospital was recruited to this study. The study was reviewed and approved by the institutional review board. Formalin-fixed paraffinembedded specimens of PanNETs could be collected from the 110 patients. Among them, 34 patients were excluded due to loss of follow-up or lack of clinical records. Finally, 76 patients were included in this study (Figure 6).

\section{Construction of tissue microarray and immunohistochemical staining}

Core tissue biopsy specimens (diameter $2 \mathrm{~mm}$ ) were obtained from individual paraffin-embedded PanNETs (donor block) and arranged in new recipient paraffin blocks (tissue array blocks) using a trephine apparatus (Superbiochips Laboratories, Seoul, Korea). Each tissue array block contained up to 50 cores, and three array blocks were prepared. An adequate sample was defined as tumor occupying more than $10 \%$ of the core area. Immunohistochemical staining was automatically performed by Leica Bond-max autostainer using Bond polymer Refine Detection kit (Leica, Wetzlar, Germany). Four- $\mu \mathrm{m}$ thick glass slides were deparaffinized, dewaxed and hydrated by drying and serial alcohol washing. Primary antibodies were reacted for 15 minutes after heat pretreatment for antigen retrieval (Epitomic retrieval solution, $100^{\circ} \mathrm{C}, 20$ minutes) and peroxidase blocking. After post primary and polymer reaction for 8 minutes, chromogenic staining was performed by $\mathrm{DAB}(3,3-$ diaminobenzidine) and counter staining by hematoxylin for 1 minute. Detailed information of primary antibody was as follows: 1) MENIN (rabbit polyclonal antibody, 1:200 dilution, Cat\# 1397-1, Epitomics); 2) ATRX (rabbit polyclonal antibody, 1:700 dilution, Cat\# HPA001906, Sigma); and 3) DAXX (rabbit polyclonal, 1:200 dilution, Cat\# HPA008736, Sigma).

\section{Immunohistochemical staining and pathological interpretation}

All three markers were positively stained in cytoplasm, nuclei, or both cytoplasm and nuclei in tumor cells. Considering the normal biologic role of three proteins in nuclei and cytoplasmic interaction with other molecules, staining pattern was assessed by 3 categories, 1) nuclear staining $(\mathrm{Nu}), 2)$ cytoplasm only $(\mathrm{Cy}), 3)$ negative $(\mathrm{N})$. Criteria of each category was 1 ) $\mathrm{Nu}$, unequivocal moderate staining in $>5 \%$ of nuclei of tumor cells with or without cytoplasmic staining; 2) $\mathrm{Cy}$, unequivocal moderate staining in $>5 \%$ of cytoplasm of tumor cells without positive stain in nuclei; 3) $\mathrm{N}$, totally negative staining in cytoplasm and nuclei of tumor cells. The assessment of immunostaining was performed

\section{Patients with pathologically}

proven PNETs $(n=177)$

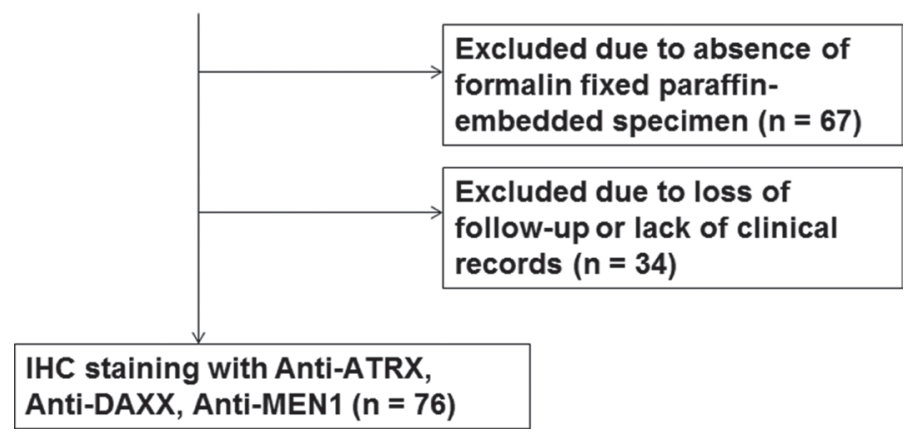

Figure 6: Flow chart of study patients. 
by two pathologists (K.B.L. and M.A.K.). We defined negative expression if the pattern was that of cytoplasmic accumulation with nuclear clearing, as long as adequate internal controls were present. When differences between the observers occurred, the slides were reinvestigated jointly by both investigators and then determined. Representative pictures of nuclear $(\mathrm{Nu})$, cytoplasmic staining (Cy) and negative (N) staining of three markers were displayed in Figure 1. MEN1 was positively stained in nuclei of non-neoplastic acinar cells which were used in internal positive control (Supplementary Figure 1A). ATRX was positively stained in macrophages or lymphocytes which were used in internal positive control (Supplementary Figure 1B). DAXX was positively stained in cytoplasm of non-neoplastic ductal epithelial cells which were used in internal positive control (Supplementary Figure 1C). Positive and negative controls were included with each staining procedure to ensure consistency between consecutive runs.

\section{Statistical analysis}

The overall survival and disease-free survival were analyzed by Kaplan-Meier method, and the significance of differences was determined by the log rank test. Multivariate analysis was performed by Cox proportional hazard regression modeling. A $P$ value of $<0.05$ was considered to be statistically important. Statistical analysis was conducted by using the IBM SPSS Statistics version 19.0 (SPSS Inc, Chicago, Il., USA).

\section{Abbreviations}

PanNETs; Pancreatic neuroendocrine tumor; IHC; Immunohistochemical staining, PDAC; Pancreatic ductal adenocarcinoma, MEN1; multiple endocrine neoplasia type1, DAXX; death-domain-associated protein, ATRX; a thalassemia/mental retardation syndrome X-linked, OS; Overall survival, DFS; disease-free survival.

\section{Authors' contributions}

Joo Kyung Park - Study concept and design; analysis and interpretation of data; drafting of the manuscript; Woo Hyun Paik- Study concept and design; analysis and interpretation of data; drafting of the manuscript; Kyoungbun Lee-Preparation of tissue specimen and the evaluation of pathologic results as well as interpretation of IHC staining data; Ji Kon Ryu - Study concept and design; interpretation of data; critical important intellectual content; study supervision; Byeong Jun Song-Acquisition of data; drafting of the manuscript; Sang Hyub Lee Acquisition of data; analysis and interpretation of data; Yong-Tae Kim - Critical revision of the manuscript for important intellectual content; analysis and interpretation of data; approval of the final version of the manuscript.

\section{CONFLICTS OF INTEREST}

None.

\section{GRANT SUPPORT}

This study was supported by Seoul National University Hospital Research Fund (grant no. 04-2011-0740).

\section{REFERENCES}

1. Eriksson B, Oberg K. Neuroendocrine tumours of the pancreas. Br J Surg. 2000; 87:129-131.

2. Yao JC, Hassan M, Phan A, Dagohoy C, Leary C, Mares JE, Abdalla EK, Fleming JB, Vauthey JN, Rashid A, Evans DB. One hundred years after "carcinoid": epidemiology of and prognostic factors for neuroendocrine tumors in 35,825 cases in the United States. J Clin Oncol. 2008; 26:3063-3072.

3. Ekeblad S, Skogseid B, Dunder K, Oberg K, Eriksson B. Prognostic factors and survival in 324 patients with pancreatic endocrine tumor treated at a single institution. Clin Cancer Res. 2008; 14:7798-7803.

4. Fredrich M, Reisch A, Illing RB. Neuronal subtype identity in the rat auditory brainstem as defined by molecular profile and axonal projection. Exp Brain Res. 2009; 195:241-260.

5. Milan SA, Yeo CJ. Neuroendocrine tumors of the pancreas. Curr Opin Oncol. 2012; 24:46-55.

6. Ballian N, Loeffler AG, Rajamanickam V, Norstedt PA, Weber SM, Cho CS. A simplified prognostic system for resected pancreatic neuroendocrine neoplasms. HPB (Oxford). 2009; 11:422-428.

7. Halfdanarson TR, Rubin J, Farnell MB, Grant CS, Petersen GM. Pancreatic endocrine neoplasms: epidemiology and prognosis of pancreatic endocrine tumors. Endocr Relat Cancer. 2008; 15:409-427.

8. Moertel CG, Frytak S, Hahn RG, O'Connell MJ, Reitemeier RJ, Rubin J, Schutt AJ, Weiland LH, Childs DS, Holbrook MA, Lavin PT, Livstone E, Spiro H, et al. Therapy of locally unresectable pancreatic carcinoma: a randomized comparison of high dose (6000 rads) radiation alone, moderate dose radiation (4000 rads +5 -fluorouracil), and high dose radiation + 5-fluorouracil: The Gastrointestinal Tumor Study Group. Cancer. 1981; 48:1705-1710.

9. Raymond E, Dahan L, Raoul JL, Bang YJ, Borbath I, Lombard-Bohas C, Valle J, Metrakos P, Smith D, Vinik A, Chen JS, Horsch D, Hammel P, et al. Sunitinib malate for the treatment of pancreatic neuroendocrine tumors. N Engl J Med. 2011; 364:501-513.

10. Strosberg JR, Fine RL, Choi J, Nasir A, Coppola D, Chen DT, Helm J, Kvols L. First-line chemotherapy with capecitabine and temozolomide in patients with metastatic pancreatic endocrine carcinomas. Cancer. 2011; 117:268-275.

11. Yao JC, Shah MH, Ito T, Bohas CL, Wolin EM, Van Cutsem E, Hobday TJ, Okusaka T, Capdevila J, de 
Vries EG, Tomassetti P, Pavel ME, Hoosen S, et al. Everolimus for advanced pancreatic neuroendocrine tumors. N Eng J Med. 2011; 364:514-523.

12. Panzuto F, Nasoni S, Falconi M, Corleto VD, Capurso G, Cassetta S, Di Fonzo M, Tornatore V, Milione M, Angeletti S, Cattaruzza MS, Ziparo V, Bordi C, et al. Prognostic factors and survival in endocrine tumor patients: comparison between gastrointestinal and pancreatic localization. Endocr Relat Cancer. 2005; 12:1083-1092.

13. Tomassetti P, Campana D, Piscitelli L, Casadei R, Nori F, Brocchi E, Santini D, Pezzilli R, Corinaldesi R. Endocrine tumors of the ileum: factors correlated with survival. Neuroendocrinology. 2006; 83:380-386.

14. Bettini R, Boninsegna L, Mantovani W, Capelli P, Bassi C, Pederzoli P, Delle Fave GF, Panzuto F, Scarpa A, Falconi M. Prognostic factors at diagnosis and value of WHO classification in a mono-institutional series of 180 non-functioning pancreatic endocrine tumours. Ann Oncol. 2008; 19:903-908.

15. Panzuto F, Boninsegna L, Fazio N, Campana D, Pia Brizzi M, Capurso G, Scarpa A, De Braud F, Dogliotti L, Tomassetti P, Delle Fave G, Falconi M. Metastatic and locally advanced pancreatic endocrine carcinomas: analysis of factors associated with disease progression. J Clin Oncol. 2011; 29:2372-2377.

16. Boninsegna L, Panzuto F, Partelli S, Capelli P, Delle Fave G, Bettini R, Pederzoli P, Scarpa A, Falconi M. Malignant pancreatic neuroendocrine tumour: lymph node ratio and Ki67 are predictors of recurrence after curative resections. Eur J Cancer. 2012; 48:1608-1615.

17. Jiao Y, Shi C, Edil BH, de Wilde RF, Klimstra DS, Maitra A, Schulick RD, Tang LH, Wolfgang CL, Choti MA, Velculescu VE, Diaz LA Jr, Vogelstein B, et al. DAXX/ ATRX, MEN1, and mTOR pathway genes are frequently altered in pancreatic neuroendocrine tumors. Science. 2011; 331:1199-1203.

18. Marinoni I, Kurrer AS, Vassella E, Dettmer M, Rudolph T, Banz V, Hunger F, Pasquinelli S, Speel EJ, Perren A. Loss of DAXX and ATRX are associated with chromosome instability and reduced survival of patients with pancreatic neuroendocrine tumors. Gastroenterology. 2014; 146:453-460 e455.

19. Haynes AB, Deshpande V, Ingkakul T, Vagefi PA, Szymonifka J, Thayer SP, Ferrone CR, Wargo JA, Warshaw AL, Fernandezdel Castillo C. Implications of incidentally discovered, nonfunctioning pancreatic endocrine tumors: short-term and long-term patient outcomes. Arch Surg. 2011; 146:534-538.

20. Modlin IM, Oberg K, Chung DC, Jensen RT, de Herder WW, Thakker RV, Caplin M, Delle Fave G, Kaltsas GA, Krenning EP,
Moss SF, Nilsson O, Rindi G, et al. Gastroenteropancreatic neuroendocrine tumours. Lancet Oncol. 2008; 9:61-72.

21. Corbo V, Dalai I, Scardoni M, Barbi S, Beghelli S, Bersani S, Albarello L, Doglioni C, Schott C, Capelli P, Chilosi $\mathrm{M}$, Boninsegna L, Becker KF, et al. MEN1 in pancreatic endocrine tumors: analysis of gene and protein status in 169 sporadic neoplasms reveals alterations in the vast majority of cases. Endocr Relat Cancer. 2010; 17:771-783.

22. Capelli P, Martignoni G, Pedica F, Falconi M, Antonello D, Malpeli G, Scarpa A. Endocrine neoplasms of the pancreas: pathologic and genetic features. Arch Pathol Lab Med. 2009; 133:350-364.

23. Yachida S, Vakiani E, White CM, Zhong Y, Saunders T, Morgan R, de Wilde RF, Maitra A, Hicks J, Demarzo AM, Shi C, Sharma R, Laheru D, et al. Small cell and large cell neuroendocrine carcinomas of the pancreas are genetically similar and distinct from well-differentiated pancreatic neuroendocrine tumors. Am J Surg Pathol. 2012; 36:173-184.

24. Jonkers YM, Claessen SM, Perren A, Schmid S, Komminoth P, Verhofstad AA, Hofland LJ, de Krijger RR, Slootweg PJ, Ramaekers FC, Speel EJ. Chromosomal instability predicts metastatic disease in patients with insulinomas. Endocr Relat Cancer. 2005; 12:435-447.

25. de Wilde RF, Edil BH, Hruban RH, Maitra A. Welldifferentiated pancreatic neuroendocrine tumors: from genetics to therapy. Nat Rev Gastroenterol Hepatol. 2012; 9:199-208.

26. Heaphy CM, de Wilde RF, Jiao Y, Klein AP, Edil BH, Shi C, Bettegowda C, Rodriguez FJ, Eberhart CG, Hebbar S, Offerhaus GJ, McLendon R, Rasheed BA, et al. Altered telomeres in tumors with ATRX and DAXX mutations. Science. 2011; 333:425.

27. Hakin-Smith V, Jellinek DA, Levy D, Carroll T, Teo M, Timperley WR, McKay MJ, Reddel RR, Royds JA. Alternative lengthening of telomeres and survival in patients with glioblastoma multiforme. Lancet. 2003; 361:836-838.

28. Ulaner GA, Huang HY, Otero J, Zhao Z, Ben-Porat L, Satagopan JM, Gorlick R, Meyers P, Healey JH, Huvos AG, Hoffman AR, Ladanyi M. Absence of a telomere maintenance mechanism as a favorable prognostic factor in patients with osteosarcoma. Cancer Res. 2003; 63:1759-1763.

29. Thompson SL, Bakhoum SF, Compton DA. Mechanisms of chromosomal instability. Curr Biol. 2010; 20:R285-295. 